\title{
Working out loud: consegue ouvir meu trabalho? ${ }^{1}$
}

\author{
Maruza Vieira Barboza Tavares, Vanessa Saldanha Pinheiro e \\ Ana Augusta Ferreira de Freitas
}

\section{RESUMO}

O objetivo deste estudo é analisar a prática de Working Out Loud (WOL) na mídia social Instagram, com vistas a compreender a maneira como essa narrativa laboral é apresentada pelos indivíduos. Para tanto, foi conduzida uma coleta de dados manual, quando perfis do Instagram foram utilizados para imersão no contexto da prática do WOL. Com uma abordagem para pesquisa de dados qualitativos nas mídias sociais, o corpus do estudo compreendeu 193 postagens que mostravam o usuário apresentando seu trabalho. Os resultados corroboram a importância do estudo do WOL para o entendimento da forma como o trabalho perpassa a vida pessoal dos indivíduos e revelam o modo como esse fenômeno abre a possibilidade para que indivíduos construam suas identidades enquanto profissionais perante o público das redes sociais, que nem sempre estão inseridos em seus ambientes de trabalho. O gerenciamento de impressões, através de legendas, tags e imagens que promovem exposições, ensinamentos e reflexões, mostra-se como elemento constituinte desse processo.

Palavras-Chave: working out loud (WOL); trabalho; mídias sociais; Instagram.

Recebido em: 15/08/2020 Revisado em: 22/12/2020 Aprovado em: 19/04/2021

Working out loud: can you hear my work?

D) Check for updates

\section{ABSTRACT}

The aim of this study is to analyze the practice of Working Out Loud (WOL) on Instagram social media, with a view to understand the way in which this work narrative is presented by individuals. For that, a manual data collection was conducted, while Instagram profiles were used for immersion in the context of the WOL practice. With an approach to search for qualitative data on social media, the corpus of the study comprised 193 posts that showed users presenting their work. Results show the importance of studying the WOL to understand the dynamics of work to individuals, as well as revealing the way in which this phenomenon opens the possibility for them to build their identities as professionals, oriented to a public who is not necessarily inserted in their work environment. The management of impressions, through captions, tags and images that promote exhibitions, teachings and reflections, is shown as a constituent element of this process.

Keywords: working out loud (WOL), work, social media, Instagram.

1 Agradecemos aos avaliadores pelo tempo alocado na avaliação do artigo e pela consistência dos comentários.

\section{Maruza Vieira Barboza} Tavares (iD,

Universidade Estadual do Ceará, Brasil Doutora em Administração

maruzacontato@hotmail.com

Vanessa Saldanha Pinheiro (iD,

Universidade Estadual do Ceará, Brasil Mestranda em Administração

vanessasp10@gmail.com

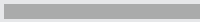

Ana Augusta Ferreira de Freitas (D),

Universidade Estadual do Ceará, Brasil Doutora em Engenharia de Produção

freitas8@terra.com.br 


\section{Introdução}

A adoção de mídias sociais como parte da vida dos indivíduos é uma realidade. Desde o surgimento dos smartphones, o acesso a essas plataformas foi intensificado pela mobilidade e conectividade, colaborando para a hiper-representação do mundo em postagens, inclusive com as práticas diárias dos indivíduos (Serafinelli, 2018). No contexto das mídias sociais, a comunicação está no cerne dos atributos dessas plataformas, posto que os indivíduos são capazes de compartilhar entre si suas vivências pessoais nas mais variadas situações, incluindo suas práticas de trabalho (Ollier-Malaterre, Rothbard, \& Berg, 2013).

Pesquisas prévias reconheceram o entrelaçamento existente entre as mídias sociais e a vida profissional dos indivíduos, tratando de temas como: a influência que as mídias sociais exercem na performance dos funcionários (Cao, Guo, Vogel \& Zang, 2016); a maneira como os empregados expõem as organizações em que trabalham nas mídias (Sergi \& Bonneau, 2016; Van Zoonen, Verhoeven \& Vliegenthart, 2016) e a identificação de como os indivíduos podem utilizar as mídias sociais para conduzir atividades relacionadas aos seus trabalhos (Leftheriotis \& Giannakos, 2014). Pouco se conhece, no entanto, sobre um fenômeno de comunicação que emergiu nesse cenário: o Working Out Loud - WOL (Sergi \& Bonneau, 2016).

O WOL é uma prática que permite que os trabalhadores se expressem, através de meios digitais, sobre seu trabalho diário e sobre o que estão fazendo e vivenciando, de uma forma semelhante às conversas que usualmente ocorrem em espaços de socialização no trabalho (Sergi \& Bonneau, 2016). Com o advento das mídias sociais, o que antes era narrado informalmente para uma pequena audiência pode agora ser compartilhado com um público maior e mais diverso. Sobre essa temática, pesquisas anteriores buscaram investigar como as postagens dos funcionários acerca do seu trabalho impactavam as organizações, evidenciando as motivações dos indivíduos e as consequências para as instituições (Van Zoonen, Verhoeven, \& Vliegenthart, 2016).

Nessa esteira teórica, estudos anteriores sobre o WOL tiveram seu foco essencialmente concentrado em mídias sociais fechadas: softwares ou plataformas virtuais internas desenvolvidas pela própria empresa, nas quais os funcionários podiam expor suas práticas de trabalho (Crump, 2017; Nicolini, 2012). Outras mídias sociais como o Instagram, reconhecido como uma plataforma pictórica e alinhada a fenômenos de exposição social com o intuito de autoapresentação (Belk, 2016), poderiam ser úteis à compreensão mais profunda desse fenômeno.

Dentro desse contexto, percebe-se que as postagens realizadas nas mídias sociais, ao passo que conferem maior visibilidade ao trabalho, podem se constituir em artefatos para compreender a formação da identidade do indivíduo enquanto profissional. Para além de perceber o WOL como uma manifestação da comunicação constitutiva das organizações, assim como foi estudado por Sergi e Bonneau (2016) no âmbito do Twitter, esse estudo propõe-se a avançar, investigando o compartilhamento do trabalho nas mídias sociais enquanto prática de autoapresentação do indivíduo como 
profissional, a partir do que este escolhe expor. Parte-se da concepção da escolha porque o ambiente online permite que os indivíduos atuem na construção de identidades por meio do gerenciamento de imagens, na medida em que o conteúdo compartilhado, por meio de posts de textos, fotos e/ou vídeos, forma uma exposição (Hogan, 2010) que tem o potencial de mostrar quem é alguém e o que ele pensa (Carroll \& Romano, 2011; Zhao, Grasmuck, \& Martin, 2008).

Desse modo, este artigo tem como objetivo analisar a prática de Working Out Loud (WOL) na mídia social Instagram, com vistas a compreender a maneira como essa narrativa laboral é apresentada pelos indivíduos. Além desta introdução, este estudo se estrutura em quatro seções. No quadro teórico, são apresentados os conceitos centrais sobre o tema. Na seção dos procedimentos metodológicos, há a apresentação da estratégia metodológica adotada. Em seguida, os resultados são apresentados e discutidos com base no arcabouço teórico. Por último, as considerações finais são discorridas.

\section{Quadro Teórico}

As mídias sociais podem ser consideradas um dos principais meios para troca de mensagens, informações e conteúdos gerados pelos usuários (Hansen, Shneiderman, \& Smith, 2011; Sergi \& Bonneau, 2016). Essas plataformas digitais ganharam espaço significativo no cotidiano dos indivíduos e, com sua crescente popularidade, transformaram diversos aspectos das suas vidas. Nesse contexto, o que se assistiu foi a uma ressignificação de questões como a vivência em sociedade, as relações interpessoais, os comportamentos em geral, as características sociopsicológicas e, até mesmo, as dinâmicas do trabalho (Hansen, Shneiderman, \& Smith, 2011). Nesse último aspecto, destaca-se o compartilhamento de conteúdo relacionado às rotinas laborais nas mídias sociais (Sergi \& Bonneau, 2016), o qual se enquadra no conceito de Working Out Loud (WOL).

Na perspectiva organizacional, o WOL pode ser considerado um fenômeno social reificado por meio da linguagem, decorrente da comunicação (Crump, 2017), que se relaciona à prática de narrar, registrar ou refletir sobre o trabalho, de forma aberta para o público em geral ou para os mais interessados, com o objetivo, a princípio, de armazená-lo, modificá-lo, melhorá-lo e, sobretudo, torná-lo observável (Latzko-Toth, Bonneau, \& Millette, 2017; Sergi \& Bonneau, 2016). Desse modo, a prática pode ocorrer através de plataformas corporativas internas, isto é, softwares desenvolvidos pela própria organização (Crump, 2017). Para além da esfera organizacional, o WOL pode ocorrer em mídias sociais externas e abertas, como Twitter, Instagram e Facebook, destinado a uma audiência que não necessariamente faz parte do ambiente de trabalho do indivíduo (Fairbairn \& Sankupellay, 2016).

No exercício do WOL, os trabalhadores geralmente falam, com uma linguagem coloquial, sobre suas tarefas diárias e sobre o que estão fazendo e experimentando no ambiente de trabalho (Sergi \& Bonneau, 2016). O WOL pode assumir uma forma dupla, sendo conversacional e textual (Sergi 
\& Bonneau, 2016), mas, para efeito deste trabalho, foram utilizados os artefatos de imagens, que consistem de uma modalidade adicional e rica de informação a ser investigada e de recursos importantes disponíveis para os usuários das mídias sociais (Serafinelli, 2018). Assim, ao atualizar suas mídias sociais com postagens, utilizando imagens associadas a legendas e hashtags sobre os aspectos relacionados ao seu trabalho, o indivíduo está praticando Working Out Loud.

Ainda refletindo sobre a perspectiva organizacional, Sergi e Bonneau (2016) reconhecem que a prática do WOL pode se manifestar de algumas formas. A primeira é quando o trabalhador expõe suas atividades em desenvolvimento, as dificuldades e interações delas decorrentes. A segunda manifestação ocorre quando há a contextualização do trabalho, mediante a descrição dos ambientes e dos recursos presentes no cenário laboral e o indivíduo destaca expertise e credibilidade através da narrativa de suas ações. Já a terceira se dá quando documenta e reporta a progressão do trabalho por conta de ações realizadas e decisões tomadas, descrevendo os métodos de conduzir o trabalho e as metas formuladas. A quarta ocorrência é quando o indivíduo se manifesta ensinando a maneira de realizar as atividades, as lições aprendidas nas resoluções de problemas e as melhores práticas. Na quinta, há a expressão de sentimentos e emoções, podendo usar sarcasmo e humor ou apresentar queixas sobre o trabalho; e, por fim, ainda pode se manifestar mediante considerações e reconhecimentos sobre o trabalho, dilemas e lutas internas, bem como reflexões sobre as decisões tomadas.

Quando se reflete sobre o fenômeno do WOL atrelado às organizações, a perspectiva da Comunicação Constitutiva das Organizações (CCO) é, para Sergi e Bonneau (2016), a base inicial para o seu entendimento, uma vez que traduz a compreensão de que a comunicação, enquanto rede de esforço cooperativo interpessoal em prol de objetivos em comum, é parte constituinte da organização (Taylor, 2009). Segundo a visão da CCO, o ambiente organizacional resulta do processo de comunicação, seja ele textual ou conversacional (Taylor \& Van Every, 2011). Neste sentido, a organização é constituída por atores humanos, como os próprios trabalhadores, e também por artefatos não humanos, como os processos, os documentos e a linguagem (Sergi \& Bonneau, 2016; Taylor, 2009).

Uma vez que as situações laborais são exploradas nas comunicações, as organizações também podem ser afetadas pelo WOL. No entanto, podem não ser consideradas totalmente como comunicações constitutivas das organizações (Schoeneborn et al., 2014), pois não fazem parte do contexto organizacional e não possuem força para fundamentar sua existência a partir da interação entre seus membros (Sergi \& Bonneau, 2016). Apesar disso, as postagens materializam a comunicação, que é um elemento fundamental capaz de revelar informações sobre o trabalho que, outrora, passariam despercebidas.

Do mesmo modo, as publicações não são meramente a transmissão de informações, posto que têm o potencial de afetar a existência das organizações e promover a colaboração laboral, ou seja, a troca de conhecimentos. Quando um indivíduo posta sobre seus processos de trabalho e um outro comenta 
ou compartilha algo de seu interesse, essa troca gera um conhecimento que colabora com as atividades em níveis individual e organizacional, podendo proporcionar ocasionalmente mudanças nas atividades e rearranjos na organização (Sergi \& Bonneau, 2016). Os estudos de Baumer, Sueyoshi e Tomlinson (2011) sobre colaboração na internet trazem evidências empíricas de como as colaborações laborais acontecem por meio da prática do WOL.

Para além dessas duas consequências, o fenômeno do WOL pode também contribuir para a construção da identidade profissional do indivíduo e da organização, à medida que permite que os indivíduos expressem suas percepções, reflexões e ponderações em relação ao trabalho (Fairbairn \& Sankupellay, 2016; Sergi \& Bonneau, 2016). Ou seja, além de influenciar transformações organizacionais, o WOL, em uma perspectiva individual, possibilita a construção da identidade do profissional (Crump, 2017). A identidade profissional é uma das identidades sociais de um indivíduo e, segundo Pimenta (2005), é ancorada nas representações, práticas e saberes profissionais, sendo dependente do exercício profissional do indivíduo.

$\mathrm{O}$ ato de revelar, nas plataformas virtuais, os seus conhecimentos e vivências sobre o trabalho não fala somente sobre atividades per se, mas também sobre si mesmo. Seguindo uma linha de raciocínio semelhante, Crump (2017) argumenta que o trabalho é cada vez mais definido não somente pelo que nós fazemos, mas por quem nós somos. Assim, quando o indivíduo decide postar aspectos do seu trabalho, este revela mais do que suas práticas laborais, pois cria uma representação do seu desempenho pessoal e da sua identidade profissional.

Desse modo, entende-se que o WOL, materializado por meio de posts de textos, fotos e/ou vídeos, forma uma exposição (Hogan, 2010) que representa o profissional que o indivíduo deseja expressar. Os indivíduos podem fabricar exibições de artefatos por meio de posts que auxiliam na construção de identidade, com a finalidade de que a audiência os tenha na mais alta estima (Hogan, 2010). Nesse sentido, conjectura-se que a prática do WOL pode auxiliar nesse processo, visto que que permite o gerenciamento de impressões e possibilita que o trabalhador agencie sua autoapresentação nas mídias sociais de forma favorável à sua imagem profissional, fabricando artefatos sobre si, que ficarão disponíveis para todos, ou para uma determinada audiência selecionada, a qualquer hora, e passíveis de acesso a partir de qualquer localização (Hogan, 2010).

Alguns estudos examinaram o papel do gerenciamento de impressão e da construção de identidade no compartilhamento de informações nas mídias sociais no contexto do trabalho. Por exemplo, Ollier-Malaterre, Rothbard e Berge (2013) discutiram a interação com colegas da esfera profissional nas mídias sociais, mostrando que pode haver um contrabalanceamento entre as identidades profissional e pessoal, a depender do que for revelado nessas plataformas. Isso sugere que as mídias sociais oferecem oportunidades para os indivíduos construírem identidades para audiências específicas (Cheung, Lee, \& Chan, 2015; Van Dijck, 2013) e por isso podem ser associadas aos processos de construção de identidade (Li, 2011; Ollier- Malaterre, Rothbard, \& Berge, 2013). 
À luz da perspectiva do gerenciamento de impressão, as mídias sociais podem ser utilizadas para transmitir uma imagem de si mesmo na tentativa de obter um objetivo profissional desejado. O gerenciamento de impressões pode ser vinculado ao uso de mídia social no contexto de trabalho (Ollier-Malaterre, Rothbard, \& Berge, 2013), pois permite que os indivíduos tornem suas experiências e os seus conhecimentos visíveis para outros (Van Zoonen, Verhoeven, \& Vliegenthart, 2016). Por outro lado, um estudo sobre a prática de cibervetting - a avaliação de funcionários em potencial a partir da sua presença online - sugere que a consciência de tais práticas levaria os indivíduos a estenderem a gestão de impressão orientada à carreira para os contextos online (Berkelaar \& Buzzanell, 2014). Ao fazer isso, os indivíduos se apresentariam como profissionais competentes e experientes, melhorando suas chances de serem considerados para outros cargos e contribuindo para alcançar o sucesso profissional (Van Zoonen \& Treemb, 2019).

Sobre a preocupação com a forma de apresentação na investigação do gerenciamento de impressões de trabalho por meio de postagens, torna-se interessante observar se as imagens são espontâneas ou montadas. As fotos espontâneas não envolvem poses e capturam pessoas agindo naturalmente. As fotos montadas são mais embelezadas, e há um planejamento da postagem realizada (Holmberg, Chaplin, Hillman, \& Berg, 2016). Embora os usuários das mídias sociais possam gostar mais de fotos montadas ou pousadas - uma vez que exercerão um maior controle sobre o resultado final -, para a audiência a impressão pode ser diferente. Postagens com fotos espontâneas podem fornecer o vislumbre de como alguém realmente é ou uma perspectiva de como se parece e se comporta quando os outros não estão olhando (Berger \& Barasch, 2018).

No entanto, os indivíduos costumam presumir que uma versão curada e polida de si mesmo irá gerar as respostas mais favoráveis e que, suavizando arestas e apresentando seu melhor lado, os outros vão gostar e querer interagir mais, quando, em alguns casos, a audiência pode preferir uma perspectiva mais autêntica (Berger \& Barasch, 2018). Desse modo, seria mais efetivo, para o gerenciamento de impressões de trabalho nas mídias sociais, o compartilhamento de momentos autênticos em vez de um cenário cuidadosamente montado para postar.

O presente trabalho irá estudar a prática do WOL em uma rede social específica, o Instagram, que utiliza imagens para facilitar as conexões entre seus usuários e estas se constituem na principal forma de comunicação (Laestadius, 2017; Oeldorf-Hirsch \& Sundar, 2016). O compartilhamento de imagens mediado pelo Instagram é um exemplo de como as conexões sociais podem ser construídas e mantidas com a plataforma atuando como uma interface para uma comunicação visual. O compartilhamento de fotos nas mídias sociais tornou-se um recurso essencial à experiência social online, em que os usuários publicam fotos variadas para expressar suas personalidades, estilos de vida e preferências (Sung, Lee, Kim, \& Choi, 2016). Corroborando esta ideia, os resultados do estudo de Oeldorf-Hirsch e Sundar (2016) dão apoio à noção de que as pessoas compartilham imagens online, principalmente para fins sociais, com vistas a se comunicar e construir relacionamentos por meio das suas postagens. 
Para o gerenciamento de impressões, a autoapresentação nas mídias sociais pode ser observada, principalmente, na forma de texto e de representação visual. No entanto, as fotos (vs. texto) são mais eficazes para a autoapresentação, uma vez que a curiosidade pela prova fotográfica confere credibilidade, o que não pode ser constatado somente por meio de textos (Marwick, 2015; Sung, Lee, Kim \& Choi, 2016). De fato, como afirmam Hum, Chamberlin, Hambright, Portwood, Schat e Bevan (2011), apesar das mídias sociais terem opções de escrever textos, legendas, disponibilizar links e vídeos, nenhuma dessas opções é mais reveladora do que as fotos.

O WOL, expresso por meio de postagens de fotos e outros elementos como legendas e hashtags, abre margem para que a reputação individual seja melhorada, uma vez que, ao materializar e revelar elementos de trabalho que permaneceriam ocultos se não fossem as publicações em mídias sociais, o sujeito está expondo a si mesmo, mostrando ao público suas habilidades e construindo sua reputação pessoal ou sua própria marca (Crump, 2017; Sergi \& Bonneau, 2016). O networking criado a partir de eventuais contatos que podem surgir em decorrência da visualização dessas capacidades laborais, por parte de outras pessoas, também pode ocasionar novas propostas de trabalho e desenvolvimento profissional (Crump, 2017). Além disso, indivíduos que expressam uma identidade profissional mais proeminente nas mídias sociais são mais prováveis de combinar conexões sociais e de trabalho nas plataformas online (Fieseler, Meckel, \& Ranzini, 2015).

Essa combinação do uso de tecnologia, trabalho e conexão social, com impacto em novas formas de rearranjo de práticas laborais, tomou uma outra dimensão em decorrência da pandemia de COVID-19, que levou bilhões de pessoas a aderiram ao distanciamento físico a fim de proteger a saúde pública, sendo este talvez o ato de cooperação mais numeroso da história (Fernandes, Biswas, Tan-Mansukhani, Vallejo, \& Essau, 2020; Zaki, 2020). Muitos trabalhos passaram a ser realizados de maneira remota, em regime de home office, e esse novo contexto de execução do trabalho de casa pode ser tomado como um comportamento pró-social, no qual os indivíduos passam a atuar, em maior proporção, como membros de uma comunidade, visando o pensamento no bem coletivo (Zaki, 2020). Durante crises ou catástrofes, a construção de identidade social pode ocorrer através do compartilhamento de experiências, inclusive profissionais (Drury, 2018). A adoção da prática do WOL, em meio à pandemia, abre a oportunidade para que o indivíduo demonstre estar passando pela mesma situação de realizar o trabalho de forma remota em seu lar, com todas as suas peculiaridades e desafios, despertando a identidade e o suporte social, bem como o sentimento de estar inserido em um grupo (Drury, 2018).

Faz-se mister destacar que a construção da identidade revelada por meio de postagens em mídias sociais não perpassa somente o âmbito individual, mas também o organizacional. À medida que os sujeitos praticam o WOL, eles também podem compartilhar as estratégias de trabalho da organização e, direta ou indiretamente, sua missão, sua visão e seus valores, fazendo com que esta seja conhecida publicamente e construindo sua reputação (Crump, 2017). As postagens feitas por usuários nas redes sociais com associação com as empresas resultam em uma divulgação involuntária, que pode ser entendida pelo público de maneira positiva ou negativa, dependendo do seu conteúdo. 
O que se sabe sobre esse assunto até o momento é que os funcionários que se identificam mais fortemente com a organização onde trabalham são mais inclinados a se envolverem em comportamentos que apoiam os objetivos de suas respectivas organizações (Van Zoonen, Van Der Meer \& Verhoeven, 2014). Sendo assim, utilizam suas mídias sociais pessoais para compartilhar notícias e informações relacionadas a produtos e serviços e até mesmo persuadir seu público para se envolver com a organização (Van Zoonen \& Treemb, 2019). Um estudo sobre as postagens no Twitter de funcionários de uma empresa revelou que estes estavam totalmente cientes do impacto potencial de suas mensagens para a organização (Van Zoonen, Verhoeven, \& Vliegenthart, 2016). Uma revisão anterior da literatura também já tinha revelado a importância dos conteúdos relacionados a trabalho postados pelos funcionários, em que estes podem atuar como "embaixadores" de suas organizações (Dreher, 2014, p.345).

\section{Procedimentos Metodológicos}

Para alcançar o objetivo proposto, a presente pesquisa valeu-se de dois dos três mecanismos indicados por Latzko-Toth, Bonneau e Millette (2017) para tornar os dados de estudos qualitativos em mídias sociais mais espessos, isto é, mais ricos, a saber: a coleta manual de dados e a observação. Esses mecanismos fazem parte de uma estratégia denominada, pelos referidos autores, de thickening e são adaptáveis, já que podem ser utilizados em conjunto ou individualmente e em diferentes plataformas virtuais. O primeiro mecanismo foi a coleta manual de rastros digitais a partir de mensagens, imagens e outros tipos de conteúdo postados pelos usuários de mídias sociais. A coleta manual de registros é particularmente proveitosa quando os limites do campo são fluidos, como no caso desta pesquisa, pois os trabalhadores que utilizam as mídias sociais para narrar seu trabalho o fazem de maneira informal, sem delimitações mais específicas. Portanto, essa abordagem mostra-se adequada na medida em que se está diante de um estudo que não possui critérios de pesquisa de dados pré-definidos em torno de um perfil sociodemográfico específico, assunto ou evento. Tais desafios clamam por uma abordagem flexível pela qual o corpus é construído através do acaso (Latzko-Toth, Bonneau, \& Millete, 2017).

As hashtags representaram o ponto de partida para o estudo do fenômeno do WOL no Instagram (Highfield \& Leaver, 2014). Assim, as postagens foram coletadas a partir da ferramenta de busca do próprio Instagram, na seção de pesquisa por tags, que têm a função de contextualizar o conteúdo compartilhado (Laestadius, 2017). Dessa forma, foi digitado \#work e, manualmente, selecionadas as fotos nas quais se identificou a narrativa de trabalho, entendida como a exposição de um acontecimento por meio de imagens. Também se consideraram as legendas e outras hashtags associadas, quando existentes. Embora a ferramenta de busca tenha sido utilizada, esta funcionou como um primeiro filtro para, a partir daí, verificar, dentro do conjunto, quais postagens realmente se enquadravam na prática do Working Out Loud. Vale ressaltar que as escolhas partiram tanto das publicações que se apresentavam como mais relevantes, quanto daquelas 
que se mostravam mais recentes no momento da pesquisa. Isto porque as mais relevantes apareceram logo no início dos resultados da pesquisa por tags. Então, primeiramente eram analisadas as que estavam em destaque e, posteriormente, as mais recentes, de acordo com a ordem do aplicativo.

As hashtags WOL e workoutloud foram buscadas, no entanto optou-se por ater-se à \#work, pois era mais explícita sobre o objetivo da pesquisa de focar em narrativas de trabalho. Além disso, as hashtags WOL e workoutloud apresentaram grande quantidade de material não relacionado ao trabalho, mas sim à prática de exercícios físicos, provavelmente por conta da expressão work out, que significa "malhar" em inglês. Havia também postagens essencialmente com viés comercial ou de publicidade empresarial, advindas de perfis institucionais, e estas foram dispensadas do corpus por não atenderem aos pressupostos do WOL. Ressalte-se que, por ser um termo globalmente empregado, não houve nenhuma filtragem em relação à geolocalização de usuários. Várias nacionalidades distintas fizeram-se presentes nas postagens coletadas e, para alguns idiomas desconhecidos pelos autores, foi utilizado um aplicativo tradutor. Quando as fotos coletadas pareceram estar repetitivas em relação ao registro do trabalho, não trazendo nenhuma novidade, considerou-se ter atingido a saturação.

As imagens foram recolhidas em dois momentos distintos: o primeiro, em março de 2019, com 119 postagens coletadas; e o segundo, em abril de 2020, com 74 postagens coletadas; resultando em 193 postagens, que passaram a compor o corpus da pesquisa. Vale ressaltar que, a princípio, o corpus da pesquisa seria constituído com as postagens coletadas em abril de 2019, mas pareceu interessante voltar a campo em março de 2020, para coletar também postagens contendo a prática do WOL durante a pandemia de COVID-19. Isso porque, uma vez que o formato de home office passou a ser adotado por muitos profissionais, percebeu-se uma oportunidade de investigar o WOL neste período de distanciamento social.

O segundo mecanismo utilizado foi a observação não participante realizada durante o mesmo período de coleta manual de rastros, que auxiliou na formação da percepção dos pesquisadores sobre o fenômeno e no entendimento acerca dos elementos, características e dinâmicas identificadas na prática do WOL. Nesse caso, os observadores não pertenciam ao grupo, nem participaram dele, assim como também não introduziram modificações no fenômeno estudado (Marietto, 2018). Ressalta-se, ainda, que a observação não participante foi direta, ou seja, foram realizadas no ambiente no qual o WOL acontecia (Instagram). Notas de campo também foram utilizadas para o registro de reflexões e interpretações sobre o contexto estudado (Marietto, 2018). Foi também nesse momento que se buscou conhecer outras postagens feitas pelo usuário e as informações postadas no seu perfil.

Para Latzko-Toth, Bonneau e Millete (2017), a utilização desses dois mecanismos (coleta manual de rastros digitais e observação), em pesquisas qualitativas dentro de mídias sociais, auxilia sobremaneira no espessamento dos dados, já que reduz a amplitude do grande número de dados e aumenta a profundidade da análise.

Em relação à interpretação dos dados, a análise de conteúdo provou-se benéfica para melhorar a profundidade dos dados rastreados, permitindo que 
os pesquisadores documentassem seu contexto de produção, identificassem novas áreas de interesse e atribuíssem sentido aos padrões emergentes (Latzko-Toth, Bonneat, \& Millete, 2017). Para Silva e Fossá (2015), a condução desse tipo de análise abrange várias etapas que são denominadas de formas variadas por diferentes autores, mesmo que as terminologias e os conceitos sejam semelhantes. Neste artigo, optou-se pelo uso das etapas propostas por Bardin (2011). A primeira refere-se à pré-análise do material, que tem como fim a organização inicial entre a teoria estabelecida no referencial e as informações relevantes que os dados podem fornecer. Nesta fase, os pesquisadores fizeram uma primeira leitura dos documentos angariados a partir da coleta manual de rastros digitais, das observações e das notas de campo.

A segunda etapa desenvolvida por Bardin (2011) diz respeito à exploração do material, cujo objetivo é construir codificações temáticas e agregar os dados em categorias simbólicas ou grupos, a partir de palavras ou frases representativas. Nesta fase, os pesquisadores analisaram o material e agruparam os prints extraídos da coleta manual, bem como as notas de campo das observações, em grupos e categorias apresentadas nos resultados.

A terceira e última etapa compreende o tratamento dos resultados, inferência e interpretação. Nesta fase, os resultados oriundos das fases anteriores são tratados mediante condução de condensação dos dados em categorias e do destaque das informações que serão analisadas. Em seguida, são realizadas interpretações inferenciais que possuem o foco, sobretudo, na análise reflexiva entre o referencial teórico e os dados, com o fim de traçar diretrizes com o que já foi exposto pela literatura e o que ainda não foi desenvolvido por este campo de pesquisa.

Outra consideração importante no processo de coleta e análise de dados é a questão de ética de pesquisa na Internet. O princípio subjacente que guiou esta pesquisa foi encontrar um equilíbrio entre os esforços para rigor empírico e a responsabilidade de proteger a privacidade das mídias sociais individuais dos usuários. Especificamente, foi conduzida uma reflexão considerando cinco dimensões para orientar as escolhas éticas: intrusão, público/privado, vulnerabilidade, dano potencial e confidencialidade (Convery \& Cox, 2012). No processo de coleta de dados, optou-se por trabalhar com os dados que estão disponíveis no domínio público. Para garantir a confidencialidade e o anonimato dos indivíduos, os rostos e os nomes nas imagens aqui apresentadas foram borrados, cuidado também adotado por outros pesquisadores da área de mídias sociais (Zhao \& Zappavigna, 2018).

Para fins de apresentação e análise dos dados, foram elencadas postagens que representavam os principais achados da pesquisa. No entanto, uma apresentação geral dos dados foi feita logo no início, conforme se apresenta na próxima seção. 


\section{Apresentação e Análise dos Dados}

Do total das 193 postagens analisadas, 119 fotos, referentes ao ano de 2019, foram feitas no próprio espaço de trabalho (escritórios, empresas, lojas e outras organizações), e 74 fotos foram feitas em casa, durante o distanciamento social, em 2020. Praticamente todas as postagens possuíam legendas (a maioria em inglês e português) e hashtags em maior ou menor quantidade, dependendo do objetivo do usuário e do contexto que este queria transmitir. Em termos gerais, a maior parte das fotos pode ser classificada como planejada (60\%), ou seja, há indícios de que houve uma preparação anterior com fins de embelezamento. Essa preocupação com a imagem a ser transmitida durante a apresentação do trabalho pode estar associada a uma construção de uma identidade profissional mais aceitável. Interessante observar, no entanto, que essa prática de apresentação do trabalho nem sempre é humanizada. Principalmente nas fotos com caráter mais reflexivo, nas quais o indivíduo normalmente não aparece e, em seu lugar, é apresentada uma imagem ou uma frase de efeito.

De uma forma geral, poucas fotos registram momentos de socialização (cerca de 17\%), indicando mais uma característica deste fenômeno do WOL como sendo algo mais individual, com o intuito principal de apresentação pessoal e não de compartilhamento de momentos de congregação social. Ainda sobre o caráter mais individualista, a grande maioria dos usuários tinham um perfil no Instagram que era essencialmente de exposição de momentos da vida privada, mas alguns possuíam também um objetivo de promover serviços profissionais por meio das postagens. Esse tipo de postagem foi mais evidenciado entre aquelas postadas durante o período de distanciamento social e atendiam a objetivos já relatados na literatura de criação de networkings e apresentação das habilidades profissionais (Crump, 2017).

Um outro dado que é importante ser ressaltado reside no fato de que parte expressiva das postagens não trazia associação com marcas de empresas ou de produtos, o que destaca o caráter mais pessoal da exposição. As postagens que traziam alguma associação o faziam por meio da marcação do local de trabalho ou por meio da marcação da organização na forma de hashtags - o que associava diretamente o indivíduo à empresa. Esse resultado mostra de que forma esse estudo avança, em termos de resultados, do que se conhecia sobre compartilhamento do trabalho em mídias sociais até o momento, já que que mostra o WOL como uma atitude individual e, em geral, dissociada de uma organização. Sobre essa atitude, percebeu-se que os indivíduos, ao perceberem as mídias sociais como meio de comunicar à audiência suas competências, melhorando suas chances no mercado de trabalho e sua imagem profissional (Van Zoonen \& Tremb, 2019), podem passar a tomar decisões sobre o que postar. Tal atitude, portanto, funciona como uma oportunidade de autoapresentação, sendo esse gerenciamento de impressões associado à construção de identidade profissional (Ollier-Malaterre, Rothbard, \& Berge, 2013).

No que diz respeito às formas de manifestação do WOL, embora pesquisas anteriores tenham enquadrado os tipos de compartilhamento em 
categorias muito bem definidas (Sergi \& Bonneau, 2016), o que se observa nessas postagens de natureza mais individualista do WOL é que há uma permanente sobreposição. A Figura 1, por exemplo, representa um trabalho feito no momento de sua execução e explicita uma das características mais proeminentes das mídias sociais: o compartilhamento da experiência em tempo real.
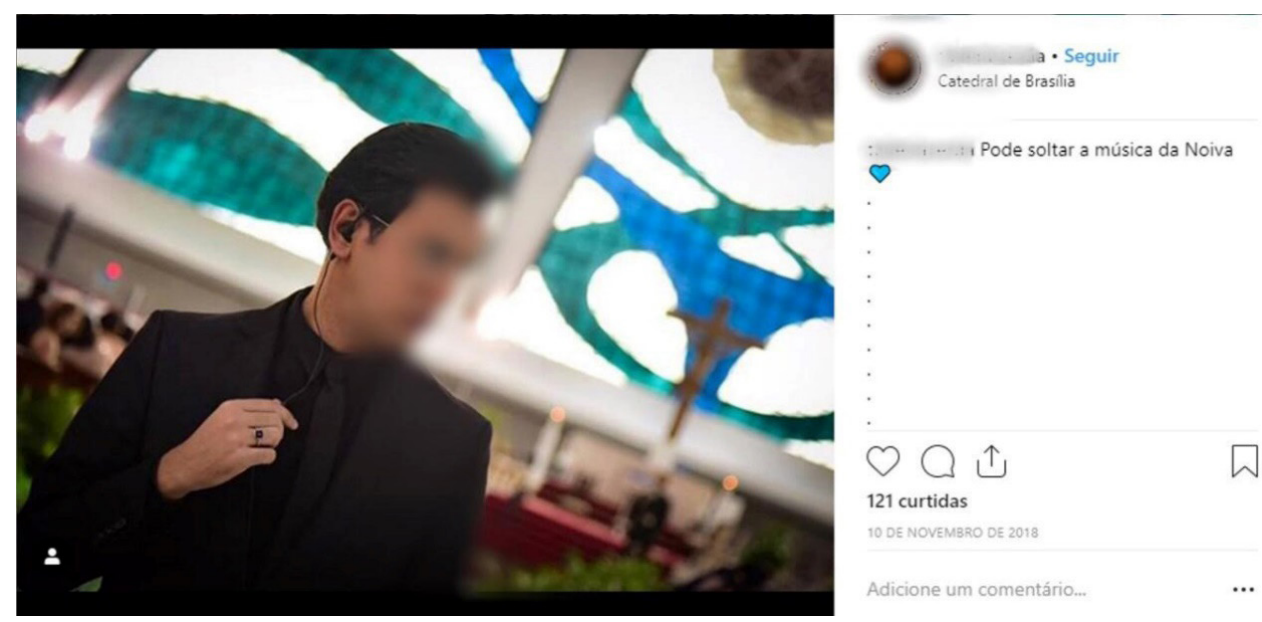

Figura 1. Compartilhamento do trabalho no momento em que está sendo realizado Fonte: Instagram (2019)

Ainda na Figura 1, as hashtags indicadas na legenda, como \#brasilia \#brazil \#work \#cerimonialista \#events \#cerimonial \#like \#fashionboy \#blogger e \#f4f, embora não vistas na imagem, podem revelar intenções do ato de publicar que passariam despercebidas. Essas intenções dizem respeito à noção de audiência e visibilidade, uma vez que as próprias hashtags possuem a função de difundir postagens cujos temas interessem a pessoas que buscam por aquilo que vem escrito após seu símbolo (\#), aumentando a sua repercussão social. Tal fato pode refletir não somente o desejo de visibilidade para si, mas também de audiência para seu próprio serviço ou para a organização em que trabalha (Dreher, 2014), mesmo que de forma velada e implícita (Crump, 2017). De fato, uma análise mais detalhada das outras postagens desse usuário mostra que a maioria é de natureza profissional, incluindo aí a associação com outras empresas que também trabalham com eventos, corroborando a literatura prévia (Fieseler, Meckel, \& Ranzini, 2015).

Ademais, as hashtags podem atuar como artefato para a gestão de impressões, pois tendem a expressar traços de personalidade e de estilo de vida, bem como algumas de suas pretensões (Crump, 2017). Por exemplo, a \#f4f indica que tem a intenção de ser popular, já que significa follow for follow, ou seja, segue quem segui-lo, ao passo que a \#blogger demonstra, até mesmo, novos anseios profissionais e a vontade de ser conhecido e reconhecido em seu nicho de trabalho (Laestadius, 2017; Oeldorf-Hirsch \& Sundar, 2016). Além disso, a \#workaholic é capaz de representar seu próprio significado de trabalho e repassar, ao público que o segue, uma imagem de profissional competente, que gosta de trabalhar 
e que é chamado para eventos em locais relevantes, como a Catedral de Brasília, conforme mostra a localização da geotagging².

Nesse ponto voltamos a um elemento anteriormente mencionado: o planejamento da foto. Bons ângulos, bons cliques e boa aparência funcionam como um tipo de marketing pessoal, fazendo com que a rede social seja uma ferramenta não somente de autoexpressão, mas também de impulsionamento do trabalho (Van Zoonen, Verhoeven, \& Vliegenthart, 2016; Van Zoonen, \& Treemb, 2019). Assim, mediante a apresentação de elementos que tangibilizam a execução do serviço, como o fone, o microfone e a igreja com altar decorado, o autor da postagem apresentada na Figura 1 parece querer promover a si mesmo e o seu trabalho. Essa foi uma manifestação muito comum nas postagens, principalmente naquelas feitas durante o período de distanciamento social, em 2020.

Em menor número, mas ainda com alguma representação, estão as postagens que contextualizam o exercício laboral, apresentando os recursos e os materiais utilizados no dia a dia de trabalho, a fim de estabelecer um terreno comum para sua profissão (Figura 2). Esse tipo de postagem dá a impressão de buscar a interação social não apenas com intuito de prestígio pessoal, visibilidade para o trabalho ou audiência profissional, mas também para criar ou fortalecer laços já existentes, motivação essa já prevista na literatura (Oeldorf-Hirsch \& Sundar, 2016).

De fato, o estabelecimento de um contexto comum busca instruir a audiência com aspectos e até vocabulários de uso costumeiro no trabalho para aproximar de si pessoas similares que executam o mesmo labor, ou se sentir parte de um grupo já existente (Crump, 2017). Isto espelha uma das características mais evidentes das mídias sociais, que é o desejo de se sentir parte de um círculo social. Quando se cria um terreno comum, é possível que se estabeleçam associações entre indivíduos daquele mesmo nicho de trabalho, formando grupos na rede para colaboração laboral.

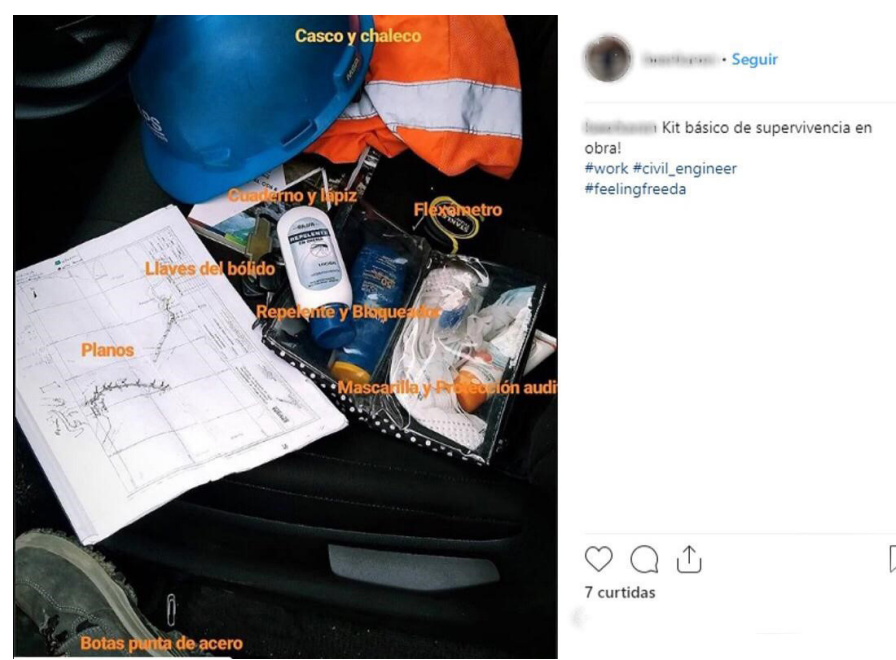

Figura 2. Apresentação dos recursos utilizados no trabalho Fonte: Instagram (2019)

2 Significa o acréscimo, na publicação, da localização ou da identificação geográfica onde a foto foi tirada. 
Nesse sentido, a prática de se mostrar pertecendo a um grupo beneficia aspectos pessoais e profissionais, uma vez que permite surgir e consolidar os networkings de cooperação laboral entre trabalhadores (Nicolini, 2012). No exemplo da foto apresentada na Figura 2, além de expor os materiais a serem utilizados, o sujeito nomeou cada um, como capacete, colete, repelente, protetor solar, caderno, lápis, bota bico de aço, máscara, protetor auricular e flexômetro, explicando que se trata de um "kit de sobrevivência na obra" e evidenciando um traço de humor na sua postagem. É importante reafirmar que a ideia da exposição e o humor empregados oportunizam que os tipos de compartilhamento desenvolvidos por Sergi e Bonneau (2016) conversem entre si e criem uma interseção entre expor, contextualizar e expressar, demonstrando novamente que não são quadrantes independentes, mas interligados, no contexto do WOL estudado.

Até aqui, verificou-se que o aspecto social é um fator de importância para o compartilhamento de experiências de trabalho e está presente em todos os tipos elaborados por Sergi e Bonneau (2016), inclusive no ato de documentar, que é uma das motivações precípuas encontradas na literatura para postagens de quaisquer experiências nas mídias socias (Oeldorf-Hirsch \& Sundar, 2016). Entretanto, no âmbito do trabalho, tal prática pode estar conectada, de maneira intrínseca, com a busca por reconhecimento pessoal e profissional (Van Zoonen \& Tremb, 2019), dado que é uma das maneiras mais evidentes de demonstrar os avanços dos serviços que estão sendo realizados. A Figura 3 ilustra essa situação.

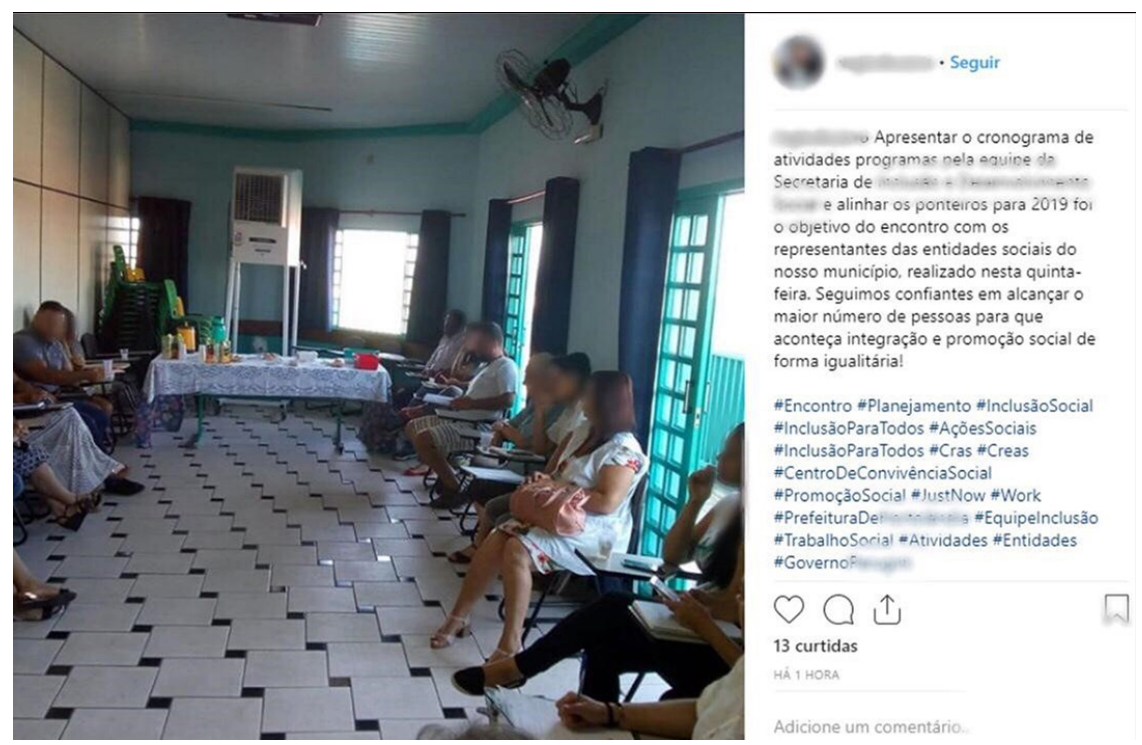

Figura 3. Reunião de prestação de contas para a comunidade Fonte: Instagram (2019)

Com apoio nas hashtags inclusão social, inclusão para todos, ações sociais e promoção social, há uma interseção entre expor, contextualizar e documentar. $\mathrm{O}$ ato de documentar pode trazer vantagens tanto no momento da divulgação quanto no futuro, assim como a sua utilização, por parte da gestão, na forma de prestação de contas de suas realizações à comunidade e no uso do post como material de novas campanhas que mostrem o interesse do potencial candidato em trabalhar para melhoria da comunidade. Além 
disso, a documentação, sendo um mecanismo de narração do trabalho, pode trazer, de forma subjacente, a busca por reconhecimento e destaque profissionais.

Interessante notar ainda que, mesmo quando a narrativa do trabalho é feita fora do contexto de uma organização, a prática de ensinar aparece nas postagens, como pode ser visto na Figura 4. Essa não é um tipo de categoria que foi comumente encontrada nas postagens de 2019, tendo aparecido de forma mais recorrente nas postagens de 2020, com os indivíduos buscando dar dicas sobre a organização do trabalho em casa durante o distanciamento social imposto pela pandemia de COVID-19.

Olhando de forma mais detalhada para o perfil da usuária da publicação a que se refere a Figura 4, vê-se que ela é professora de uma instituição de ensino superior. Sabe-se que publicações que trazem ensinamentos também guardam vantagens para a própria organização em que o indivíduo trabalha, mesmo que não haja interferência alguma desta na publicação. Esta prática pode, assim, estimular diálogos com outros profissionais na própria postagem ou, posteriormente, fortalecer laços já constiuídos (Oeldorf-Hirsch \& Sundar, 2016) e propiciar novas cooperações de trabalho, fazendo com que a organização já existente se adapte a outras realidades que se apresentem ou que novas organizações surjam a partir dessas interações. Nota-se ainda uma sutil interseção entre expor, ensinar e expressar o trabalho, embora se entenda que a característica de ensino esteja mais evidente.

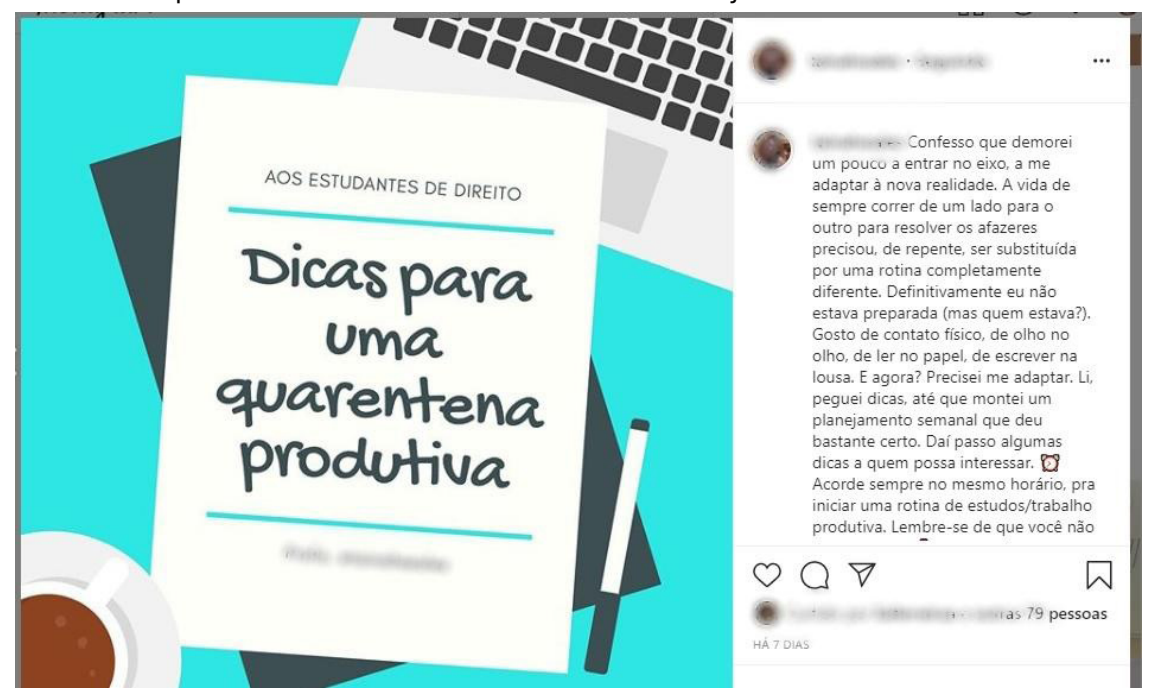

Figura 4. Narrativa de como melhorar o trabalho

Fonte: Instagram (2020)

Expor, contextualizar, documentar e todas as outras formas pelas quais o WOL se apresenta nada mais são do que meios de se autoexpressar. O ato de se expressar revela-se como um meio de compartilhar com o público aspectos de sua vivência laboral que, outrora, poderiam ser discutidos em espaços comuns de descanso no trabalho, entre amigos, ou até mesmo passariam despercebidos, se não fosse o uso das mídias virtuais. Nesse contexto, a Figura 5 ilustra uma situação na qual o indivíduo apresenta máquinas operando e trabalhando, em condições de frio extremo. O indivíduo descreve a situação com humor e escreve na legenda que não 
sabe o que é pior: se seria a direção de metal congelada ou o colega de trabalho olhando para ele. Publicações pessoais desse cunho podem expressar emoções, sentimentos, humor e, até mesmo, reclamações, que constroem sua identidade ante o seu público, por meio da narrativa do trabalho (Crump, 2017).

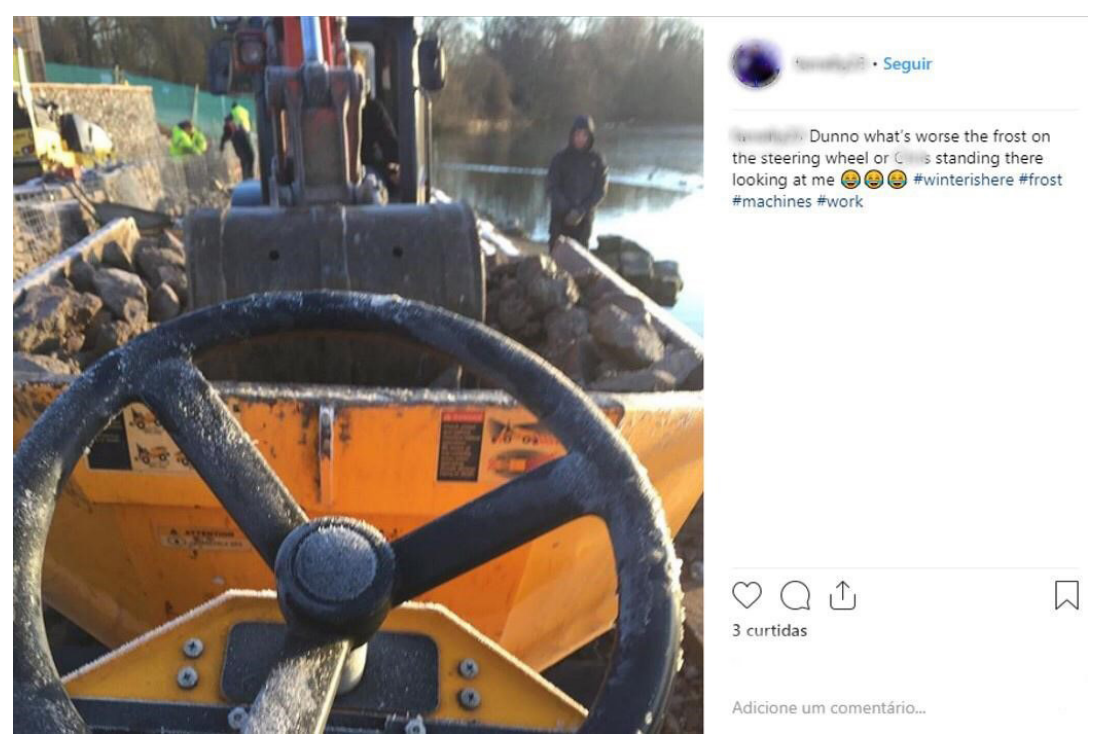

Figura 5. Narração laboral com humor Fonte: Instagram (2019)

A construção de uma identidade é favorecida por narrações que trazem reflexões sobre a atividade laboral. Refletir sobre o trabalho é a mais clara e explícita expressão do significado deste para os indivíduos. Ao compartilharem seus pensamentos com o público, há a possibilidade, inclusive, de ressignificar aquilo que já tinha um conceito pessoal definido, como sua própria prática laboral. A Figura 6 representa este tipo de postagem, pois o sujeito compartilha suas considerações e suas reflexões com a audiência, bem como pondera e avalia decisões tomadas em relação à sua carreira profissional.

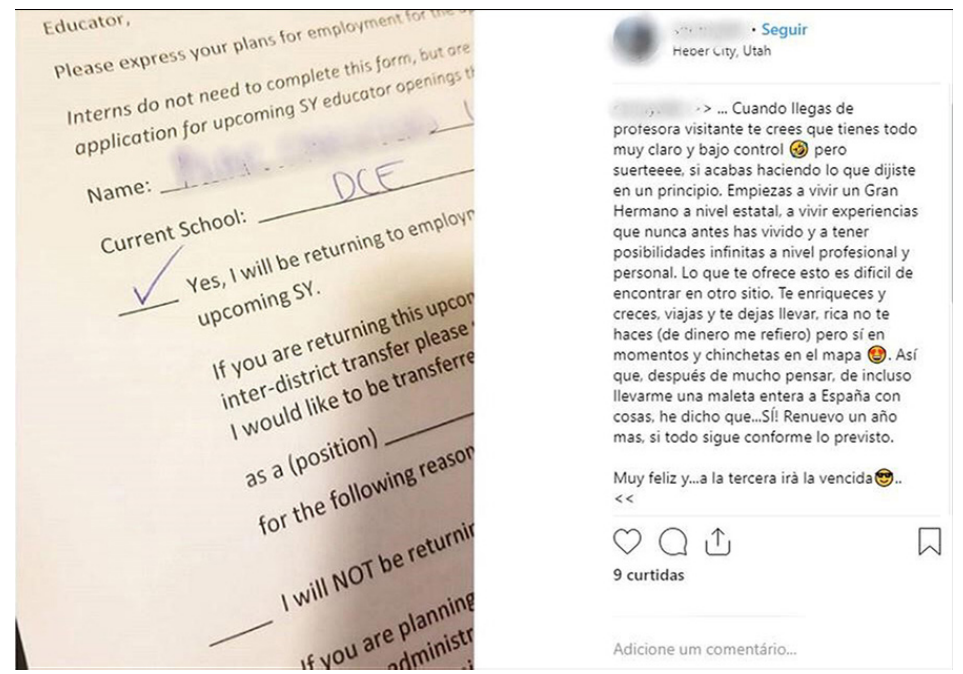

Figura 6. Pensando de maneira reflexiva sobre 0 trabalho

Fonte: Instagram (2019) 
Até o momento, vimos que o WOL se apresenta como uma prática que tem o poder de apresentar, pelas mídias sociais, documentação sobre o trabalho e seu contexto, assim como expressar as emoções a ele vinculadas. Notadamente, a prática também tem o potencial de ensinar novos meios de se organizar, conforme transformações aconteçam. O que vem acontecendo em termos de home office por conta da pandemia de COVID-19 é um exemplo disso e já foi apresentado. Por mais que não seja o objetivo precípuo desta pesquisa, é possível estabelecer conexões e comparações entre o período anterior e o período corrente, no quesito do exercício de WOL, nos propósitos de compartilhamento e nas contribuições para identidade do indivíduo enquanto trabalhador.

Publicações de escritórios improvisados em casa são recorrentes no Instagram, e as legendas registram relatos, reflexões e até desabafos sobre a nova dinâmica de trabalho, como na Figura 7. Os equipamentos, as cadeiras e as mesas de reuniões foram substituídas por salas virtuais, nas quais a comunicação é realizada por câmeras, fones e microfones. Os companheiros de trabalho agora são os familiares e até os animais de estimação que, vez ou outra, surgem em publicações com traços de humor, como forma de expressão para escapar de um período carregado de negatividade e ter algum ponto de descontração.
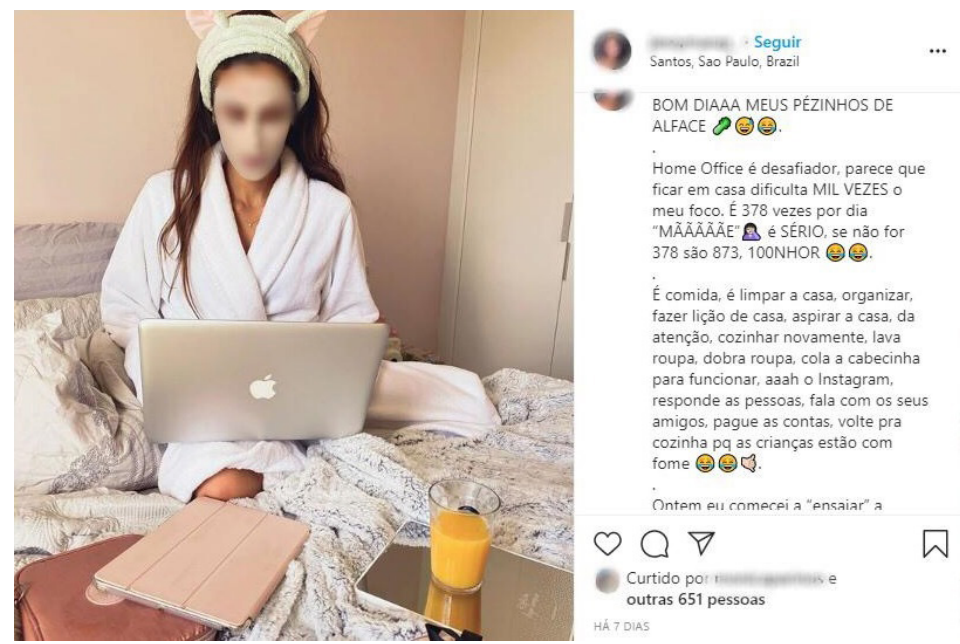

Figura 7. 0 trabalho de home office em meio à pandemia de COVID-19 Fonte: Instagram (2020)

As mídias sociais findaram por se tornar um local de ainda mais destaque nesse período, uma vez que a necessidade de isolamento social impede que os indivíduos possam se encontrar pessoalmente para dialogar. É certo que a busca por reconhecimento profissional e destaque social ainda se faz presente, entretanto, agora, é possível perceber a interação social, mesmo que por meio de postagens sobre trabalho, como uma das formas mais puras e simples do desejo em manter os laços sociais ou simplesmente escapar da realidade (Fernandes et al., 2020). No momento de pandemia, expressar-se pela postagem de home office sobre como está lidando com o momento desafiador desperta a identificação e suporte social, além do sentimento de pertencimento a um grupo, uma vez que existem muitos profissionais na mesma situação (Drury, 2018). 
O uso do Instagram, rede social escolhida nesta pesquisa, já foi associado tanto ao escapismo quanto à plataforma para exposição social. No caso das postagens específicas sobre o contexto de trabalho, aparentemente também se somam outros estímulos, como a busca por audiência para si e para o seu serviço, visibilidade e prestígio. Essas postagens podem atuar no processo de construção da identidade do trabalhador, e o seu conteúdo pode ser deliberadamente fabricado em um processo de gerenciamento de impressões (Ollier-Malaterre, Rothbard, \& Berge, 2013). Desse modo, o indivíduo pode conduzir sua autoapresentação profissional montando uma exposição que evidencia o que deseja, e estes artefatos ficarão disponíveis para o acesso da audiência sem delimitação de tempo e localização geográfica (Hogan, 2010).

No caso das postagens realizadas no período da COVID-19, há um evidente aumento da apresentação de serviços profissionais em perfis pessoais abertos. E, nesse contexto, apresentar-se com uma luz favorável pode ser essencial, principalmente quando as postagens têm o intuito de mostrar aos outros e às organizações que buscam profissionais por meio da análise das mídias sociais a experiência e o conhecimento que os indivíduos detêm. Tal consciência leva-os a praticarem uma cuidadosa exposição de si ou, como tratado no referencial teórico, a um premeditado gerenciamento de impressão.

A apresentação nas mídias sociais é utilizada como suporte digital para melhorar a apresentação do indivíduo e isso pode explicar o grande número de fotos planejadas. Ademais, uma análise das postagens mostra tanto o reforço da identidade profissional quanto da identidade social, dado que, a partir da autoapresentação, o indivíduo se identifica por meio de interesses comuns com outros membros da audiência - como aqueles que se encontram em uma situação de home office. Essas ações levam à reflexão de que a narrativa do trabalho pode ser protagonista ou coadjuvante, mas em todas as situações é utilizada para transmitir a mensagem dos usuários para seus receptores.

Essa transmissão ocorre das mais diversas formas e em lugares diversos, resultado da ubiquidade dos smartphones. Há fotos feitas no local do trabalho, no trajeto de e para o trabalho e em momentos de relaxamento após a realização das tarefas. De particular interesse para esse trabalho, estão aquelas de cunho pessoal que acabam refletindo, mesmo que indiretamente, a imagem organizacional para o público. Isso porque o impacto pode ou não ser favorável para a reputação da organização. A Figura 8 mostra um exemplo desse entrelaçamento.
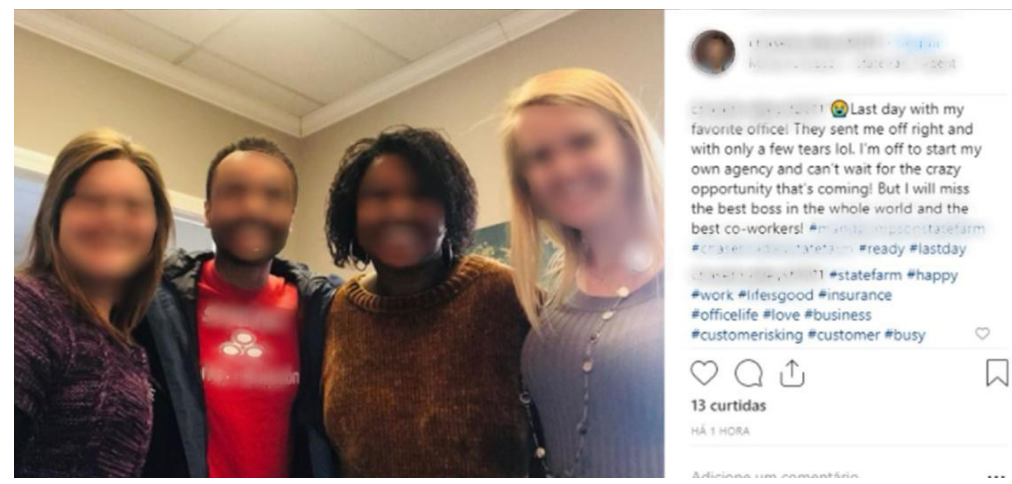

Figura 8. Exemplo de postagem pessoal com associação com a organização

Fonte: Instagram (2019) 
A foto mostra a despedida de uma funcionária de uma empresa, na qual ela agradece a oportunidade e engrandece a qualidade do convívio com os colegas. Não se pode descartar a possibilidade de que imagens como essa tenham apenas o intuito de estabelecer conectividades para fins sociais. Porém, ao associarem sua narrativa ao ambiente organizacional, nesse caso, em particular, levantando um aspecto positivo da organização, acabam por afetá-la, e este fenômeno acaba por sair do controle da organização. A seção seguinte traz as considerações finais do trabalho.

\section{Considerações Finais}

O Working Out Loud estabeleceu-se como uma prática de observação e narração de processos de trabalho, vinculada essencialmente à esfera organizacional como meio para entender os elementos de comunicação que a constituem. As mídias sociais corroboraram para que tal prática se consolidasse e abriram a possibilidade para que o fenômeno fosse analisado para além do campo organizacional, dentro de uma perspectiva mais individual. Este trabalho teve como objetivo analisar a prática de Working Out Loud (WOL) na mídia social Instagram, com vistas a compreender a maneira como essa narrativa laboral é apresentada pelos indivíduos. Na pesquisa, nem todas as postagens estão relacionadas ao momento da realização do trabalho, mas todas têm relação direta com o trabalho e representam a forma como o indivíduo resolveu expressá-lo e apresentá-lo para uma audiência.

$\mathrm{Na}$ perspectiva individual, a narrativa do trabalho expressa por meio de postagens na rede social abre a possibilidade para que se analise a construção de identidade do indivíduo como profissional, por meio dos seus ensinamentos, contextualizações e reflexões sobre o trabalho. Muito embora não seja possível identificar as reais motivações para o compartilhamento, já que os usuários não foram diretamente contatados, há nesse trabalho um esforço para compreender o intuito das postagens. O que pode se depreender, de forma geral, é que há um esforço no sentido de estabelecimento de laços sociais com uma audiência que às vezes é mais ampla, quando o indivíduo simplesmente se apresenta no trabalho, ou mais próxima, quando se direciona a um público que fala a mesma linguagem.

Ademais, criam-se, por meio das narrativas do trabalho, oportunidades de crescimento e impulsionamento da carreira, dentro de um perfil nas redes sociais que é um amálgama entre momentos da vida pessoal e profissional. O usuário parece ter alguma consciência disso ao se apresentar em uma luz favorável por meio de fotos planejadas e legendas que descrevem as habilidades que acredita possuir. Diferentemente, no entanto, de pesquisas anteriores conduzidas na perspectiva das empresas, os indivíduos falam sobre os seus trabalhos sem objetivos claramente definidos em relação ao que pretendem expressar através de sua narrativa laboral, conduzindo associações com imagens e outros recursos da mídia social que envolvem contexto, ensino, exposição e/ou reflexão.

Embora não tenha sido o objetivo principal do trabalho, foi possível estabelecer algumas análises sobre as narrativas laborais antes e após o 
período de distanciamento social imposto pela pandemia de COVID-19. Considerando a possibilidade, já reconhecida, de as mídias sociais serem um refúgio para usuários durante a crise, inconteste é o fato de que as postagens acontecem em grande número e passam a ser mais voltadas a uma mescla de apresentação da vida pessoal e das habilidades profissionais, incluindo a propaganda de serviços. Talvez por não se sentirem tão confortáveis em relação ao visual dos novos ambientes de home office, os indivíduos aparecem de forma menos frequente e, como era de se esperar, há menos socialização nas postagens. Na falta de uma socialização direta, um pretenso apoio social vem na forma de dicas sobre como superar os novos obstáculos do trabalho.

Em termos de contribuições teóricas, esta pesquisa avança no conhecimento acerca da prática do WOL, na medida em que o analisa como fenômeno para além de uma narrativa laboral e de uma forma de comunicação organizacional. Uma vez que o WOL permite que o trabalhador expresse quem é, o presente estudo apoiou-se no conhecimento sobre gerenciamento de impressões nas mídias sociais para estender o conhecimento já existente sobre Working Out Loud à perspectiva individual, isto é, à identidade do indivíduo enquanto profissional. Haja vista que publicações sobre trabalho podem falar muito sobre si e tendo em mente uma audiência específica que acessará seu perfil a qualquer hora e de qualquer lugar, os indivíduos podem apresentar seus conhecimentos e competências profissionais, ou mesmo expor suas atividades e reflexões, sendo cada postagem uma oportunidade de se autoapresentar, gerenciando impressões que podem ser associadas à construção de sua identidade profissional.

Em termos de implicações, algumas raras postagens fazem uma associação entre a exposição do trabalho que o indivíduo escolhe realizar e o nome de empresas e/ou marcas. Essa associação parece uma ação unidirecional - do usuário para o seu público - que, nesse caso, é o mais amplo possível já que só foram examinados perfis abertos. De alguma forma, as empresas deveriam ter consciência dessas postagens, pois a mesma prática que pode construir uma identidade profissional pode também afetar a imagem organizacional, de forma positiva ou negativa.

Em termos de limitação, o fato de a coleta de dados não ser circunscrita a nenhum tipo de organização impede avaliar em que medida essas práticas poderiam influenciar na colaboração laboral. Adicionalmente, registra-se como limitação o fato de os usuários das redes sociais não terem sido diretamente acessados. Acredita-se que a condução de novas pesquisas delimitadas a um determinado grupo de funcionários poderia refletir melhor sobre o impacto das postagens no nível organizacional, assim como o contato com os usuários poderia esclarecer mais adequadamente as motivações das suas postagens relativas ao trabalho. A condução de estudos futuros para investigar o WOL por meio de outras estratégias de coleta de dados deve ainda auxiliar na compreensão das estratégias utilizadas para o gerenciamento de impressões e para a construção da identidade profissional. 


\section{Referências}

Bardin, L. (2011). Análise de conteúdo. SP: Edições 70.

Baumer, E. P. S., Sueyoshi, M., \& Tomlinson, B. (2011). Bloggers and readers blogging together: collaborative co-creation of political blogs. Computer Supported Cooperative Work (CSCW), 20(1-2), 1-36. https://doi.org/10.1007/s10606-010-9132-9

Belk, R. (2016). Extended self and the digital world. Current Opinion in Psychology, 10, 50- 54. https://doi.org/10.1016/j.copsyc.2015.11.003

Berger, J., \& Barasch, A. (2018). A candid advantage? The social benefits of candid photos. Social Psychological and Personality Science, 9(8), 1010-1016. https://doi. org/10.1177/1948550617732390

Berkelaar, B. L., \& Buzzanell, P. M. Cybervetting, Person-Environment Fit, and Personnel Selection : Employers' Surveillance and Sensemaking of Job Applicants' Online Information. Journal of Applied Communication Research, 42(4), 456-476. https://doi.org/10.1080/00909882.2014.954595

Cao, X., Guo, X., Vogel, D., \& Zhang, X. (2016). Exploring the influence of social media on employee work performance. Internet Research, 26(2), 529-545. https://doi.org/10.1108/IntR-11-2014-0299

Carroll, E., \& Romano, J. (2011) Your digital afterlife: when Facebook, Flickr and Twitter are your estate, what's your legacy? Berkeley, CA: New Riders.

Cheung, C., Lee, Z. W., \& Chan, T. K. (2015). Self-disclosure in social networking sites: the role of perceived cost, perceived benefits and social influence. Internet Research, 25(2), 279-299. https://doi.org/10.1108/IntR-09-2013-0192

Convery, I., \& Cox, A. (2012). Review of research ethics in internet-based research. Practitioner Research in Higher Education, 6, 50-57.

Crump, H. (2017). An investigation into the phenomenon and Discourse of Working Out Loud. Master Thesis in Educational Technology. The Open University. Institute of Education Techonology. http://dx.doi.org/doi:10.21954/ou.ro.0000cf21

Dreher, S. (2014). Social media and the world of work. Corporate Communications: An International Journal, 19(4), 344-356. https://doi.org/10.1108/CClJ-10-2013-0087

Drury, J. (2018). The role of social identity processes in mass emergency behaviour: an integrative review, European Review of Social Psychology, 29(1), 38-81. https://doi.org/10.1080/10463283.2018.1471948

Fairbairn, L. D., \& Sankupellay, M. (2016). Twitter Out Loud: connecting people in organisations. $\mathrm{OzCHI}$ '16, Launceston, Australia. http://dx.doi. org/10.1145/3010915.3010966

Fieselerl, C., Meckel, M., \& Ranzini, G. (2015). Professional personae-how organizational identification shapes online identity in the workplace. Journal of Computer-Mediated Communication, 20(2), 153-170. https://doi.org/10.1111/ jcc4.12103

Fernandes, B., Biswas, U. N., Tan-Mansukhani, R, Vallejo, A., \& Essau, C. (2020). The impact of COVID-19 lockdown on internet use and escapismo in adolescentes. Revista de Psicología Clínica com Niños y Adolescentes, 7(3), 59-65 
Hansen, D., Shneiderman, B., \& Smith, M. (2011). Analyzing social media networks with NodeXL: Insights from a connected world. Boston: Elsevier.

Highfield, T., \& Leaver, T. (2014). A methodology for mapping Instagram hashtags, First Monday, 20(1). https://doi.org/10.5210/fm.v20i1.5563

Hogan, B. (2010). The presentation of self in the age of social media: distinguishing performances and exhibitions online. Bulletin of Science, Technology \& Society, 30(6), 377- 386. https://doi.org/10.1177/0270467610385893

Holmberg, C., Chaplin, J. E., Hillman, T. \& Berg, C. (2016). Adolescents' presentation of food in social media: an explorative study. Appetite, 99, 121-129. https://doi. org/10.1016/j.appet.2016.01.009

Hum, N., Chamberlin, P., Hambright, B., Portwood, A., Schat, A., \& Bevan, A. (2011). A picture is worth a thousand words: a content analysis of Facebook profile photographs. Computers in Human Behavior, 27, 1828-1833. https://doi. org/10.1016/j.chb.2011.04.003

Laestadius, L. (2017). Instagram. In L. Sloan \& A. Quan-Haase (Orgs.). The SAGE Handbook of Social Media Research Methods. London: SAGE Publications.

Latzko-Toth, G., Bonneau, C., \& Millette, M. (2017). Small data, thick data: thickening strategies for trace-based social media research. In L. Sloan \& A. Quan-Haase (Orgs.). The SAGE Handbook of Social Media Research Methods. London: SAGE Publications.

Leftheriotis, I., \& Giannakos, M. N. (2014). Using social media for work: losing your time or improving your work? Computers in Human Behavior, 31, 134-142. https://doi.org/10.1016/j.chb.2013.10.016

Li, D. C. (2011). Online social network acceptance: a social perspective. Internet Research, 21(5), 562-580.

Marietto, M. (2018). Observação participante e não participante: contextualização teórica e sugestão de roteiro para aplicação dos métodos. Revista Ibero-Americana de Estratégia, 17(4), 05-18. doi: 10.5585/ijsm.v17i4.2717

Marwick, A. (2015). Instafame: luxury selfies in the attention economy. Public Culture, 27, 136-160. https://doi.org/10.1215/08992363-2798379

Nicolini, D. (2012). Pratice theory, work and organization: an introduction. Oxford: Oxford University Press.

Oeldorf-Hirsch, A., \& Sundar, S. (2016). Social and technological motivations for online photo sharing. Journal of Broadcasting \& Eletronic Media, 60(4), 624-642. https://doi.org/10.1080/08838151.2016.1234478

Ollier-Malaterre, A., Rothbard, N., \& Berg, J. (2013). When worlds collide in cyberspace: how boundary work in online social networks impacts professional relationships. Academy of Management Review, 38(4), 645- 669. https://doi. org/10.5465/amr.2011.0235

Pimenta, S.G. (2005). Saberes pedagógicos e atividade docente. São Paulo: Cortez.

Schoeneborn, D., Blaschke, S., Cooren, F., McPhee, R. D., Seidl, D., \& Taylor, J. R. (2014). The three schools of CCO thinking: interactive dialogue and systematic comparison. Management Communication Quarterly, 28(2), 285-316. https://doi. org/10.1177/0893318914527000 
Serafinelli, E. (2018). Digital life on Instagram: new social communication of photography. Bingley: Emerald Publishing.

Sergi, V., \& Bonneau, C. (2016). Making mundane work visible on social media: a CCO investigation of working out loud on Twitter, Communication Research and Practice, 2(3), 378-406. https://doi.org/10.1080/22041451.2016.1217384

Silva, A. H., \& Fossá, A. H. (2015). Análise de conteúdo: exemplo de aplicação da técnica para análise de dados qualitativos. Qualit@s Revista Eletrônica, 17(1).

Sung, Y., Lee, J., Kim, E., \& Choi, S. (2016). Why we post selfies: understanding motivations for posting pictures of oneself. Personality and Individual Differences, 97, 260-265. https://doi.org/10.1016/j.paid.2016.03.032

Taylor, J. R. (2009). Organizing from the bottom up? Reflections on the constitution of organization in communication. In L. L. Putnam \& A. M. Nicotera (Eds.). Building theories of organization: the constitutive role of communication (153-186). New York, NY: Routledge.

Taylor, J. R., \& Van Every, E. J. (2011). The situated organization: case studies in the pragmatics of communication research. New York, NY: Routledge.

Van Dijck, J. (2013). 'You have one identity': performing the self on facebook and Linkedln. Media. Cult. Soc. 35(2), 199-215. https://doi.org/10.1177/0163443712468605

Van Zoonen, W, \& Treemb, J. (2019) The role of organizational identification and the desire to succeed in employees' use of personal twitter accounts for work. Computers in Human Behavior, 100, 26-34. https://doi.org/10.1016/j.chb.2019.06.008

Van Zoonen, W., Van Der Meer, G. L. A., \& Verhoeven, J. W. M. (2014). Employees workrelated social-media use: His master's voice. Public Relations Review, 40(5), 850-852. https://doi.org/10.1016/j.pubrev.2014.07.001

Van Zoonen, W., Verhoeven, J., \& Vliegenthart, R. (2016). How employees use Twitter to talk about work: a typology of work-related tweets, Computers in Human Behavior, 55, 329-339. https://doi.org/10.1016/j.chb.2015.09.021

Zaki, J. (2020). Catastrophe compassion: understanding and extending prosociality under crisis. Trends in Cognitive Sciences. https://doi: 10.1016/j.tics.2020.05.006 [Epub ahead of print].

Zhao, S., Grasmuck, S., \& Martin, J. (2008) Identity construction on Facebook: digital empowerment in anchored relationships. Computers in Human Behavior, (24), 18161836. https://doi.org/10.1016/j.chb.2008.02.012

Zhao, S., \& Zappavigna, M. (2018). Beyond the self: intersubjectivity and the social semiotic interpretation of the selfie. New media \& society, 20(5), 1735-1754. https:// doi.org/10.1177/1461444817706074 